\title{
KARANIWANG GRAMATIKANG PAGKAKAMALI SA PAGSULAT NG SANAYSAY TUNGO SA LINGGUWISTIKONG KASANAYAN
}

\author{
Antonio C. De Los Reyes \\ Laguna State Polytechnic University
}

Article DOI: https://doi.org/10.36713/epra7727

DOI No: 10.36713/epra7727

\begin{abstract}
Ang pag-aaral na ito ay layuning kilalanin, ilarawan, ipangkat at suriin ang mga karaniwang gramatikang pagkakamaling mga Senior High School sa pagsulat at kaalaman sa linggwistikong kasanayan.

Ang mananaliksik ay gumamit ng pamamaraan ng deskriptibong pananaliksik kasama ng pag-aanalisa ng datos. Binigyang pansin ng pananaliksik na ito ang mga salik na nakakaapekto sa paggawa ng mali sa gramatika ng Senior High School sa Technical-Vocational-Livelihood Industrial Arts Shielded Metal Arc Welding, TechnicalVocational-Livelihood Home Economics Caregiving at Academic-Humanities and Social Sciences ng Buenavista Integrated National High School para sa taong 2020-2021 at ginamitan ng istatistikal na pamamaraang weighted mean at standard deviation na pagsulat. Mga tanong ang ginamit upang makalap ang mga salik na nakakaapekto sa mga mag-aaral sa paggawa ng mali sa gramatika sa pagsulat ng Filipino. Ang ginamit na istatistikal na pamamaraan at statistically treatment para malaman ang porsyento at karaniwang pagkakamali sa gramatika.

Ang kabisaan sa pagkatuto ng mga mag-aaral sa pagsulat ng sanaysay sa Filipino ay naging positibo at tinanggap ng mananaliksik batay sa mga naging sa mga tanong at pagsusulit na ginawa. Ayon sa mga krayteryang inilahad sa pagtatanong at pagtataya ay naging resulta na may kabuuang interpretasyong mataas.

Ang antas ng kaalaman na ipinakita ng mga mag-aaral sa lingguwistikong kasanayan sa pagtataya na may kinalaman sa istruktura ng salita, pagbuo ng pangungusap, at bokabularyo / pangkahulugan ng salita ang naging resulta ay may kabuuang interpretasyon na kasiya-siya.

Ang antas ng kaalaman ng mga mag-aaral na ipinamalas sa pagsulat ng sanaysay sa antas ng kaalaman sa lingguwistikong kasanayan, ay ipinakita din ng datos na nakalap na walang bisang palagay na "walang makabuluhang kaugnayan ng mga salik panghikayat sa pagsulat ng sanaysay sa antas ng kaalamang lingguwistikong kasanayan ng mga tagatugon", sa pagkatuto ng mga mag-aaral batay sa pagsulat ng sanaysay ay nakakuha ng "May makabuluhang" Kaugnayan sa pagitan nila.

Sa mga guro, sa Junior High School at Senior High School sa asignaturang Filipino, Ipagpatuloy natin ang magandang simulain at pagbuo ng mga kagamitang pagtuturo na maaaring makatulong at mahikayat ang mga mag-aaral na magsanay na mabuti sa Asignaturang Filipino at sa iba Asignatura. Ipagpatuloy na mapaunlad ang sariling

kasanayan upang makabuo ng iba't ibang Estratehiya sa pagtuturo ng tamang pagsulat ng sanaysay at huwag mapagod sa pagwawasto ng mga sulatin ng mag-aaral at iyon ng sa gayon ay gawin nang maging magaling ang mga mag-aaral sa pagsulat ng iba't ibang sulatin.

Sa mga mag-aaral, mahalin, igalang ang mga guro na walang sawa sa pagbibigay ng kaalaman at seryosohin at sikaping mapahalagahan ang mga kagamitang pagtuturo na inihahanda ng guro. Sikaping makakuha ng magandang marka sa mga pagsusulit na ibinibigay ng guro, ito man ay pasalita o pasulat.

Sa susunod na mananaliksik, iminumungkahing irebisa pa ng husto ang ginawang pag-aaral hinggil sa Karaniwang Gramatikang Pagkakamali sa Pagsulat ng Sanaysay Tungo sa Lingguwistikong Kasanayan.
\end{abstract}




\section{SJIF Impact Factor 2021: 8.013| ISI I.F.Value:1.241| Journal DOI: 10.36713/epra2016

\section{PANIMULA}

Layunin ng mananaliksik na bigyang pansin ang salik ng panghikayat at ang pangkaraniwang pagkakamali ng pang gramatika na nagagawa ng mga mag-aaral ng Senior High School sa Technical-Vocational-Livelihood Industrial Arts Shielded Metal Arc Welding, Technical-Vocational-Livelihood Home Economics Caregiving at Academic-Humanities and Social Sciences sa asignaturang Filipino upang hindi na nila paulit-ulit na gawin ang pagkakamali sa kanilang mga sulatin. Ang saliksik na ito ay nais mabuksan ang kamalayan ng mga mag-aaral upang malaman ang kahalagahan ng tamang pagsulat at malinang ang kanilang galing dito.

Hindi maikakaila na mahalaga ang lenggwaheng Filipino, dahil ito ay ating ginagamit sa pakikipagkumunikasyon. Ito rin ay ikinokonsidera bilang lenguwaheng pang buong mundo, lalo na sa komersya, midya, kultura, disenyo at edukasyon. Ikinukonsidera ang Filipino bilang unang lenguwahe sa Pilipinas.

Ang mga mag-aaral na mahina sa Filipino ay nagkakamali sa pagsulat na gawain. Kahit ang Filipino ay pormal na ipinapakilala sa mura pang edad, sa day care o kinder, marami pa rin ang nagkakamali sa gramatika kahit sila ay nasa Senior High School na ng pagsulat sa Filipino.

Ang pagkakamali ay repleksyon ng pangkaisipang aktibidad ng mag-aaral at nagsasabing ito ay may malaking kinalaman tungkol sa panloob na proseso sa produksyon ng lenguwahe. Kung kaya ang pag-aanalisa sa mali ay may positibong katugunan. Ang pagkatutoo ay nakabase sa tuloy-tuloy na paghahayag at tamang pagpapalagay, ang pagsubok at susog na ideya sa kanila. (Bartholome 2014)

Sa kabilang banda, mahalagang matulungan ang mga mag-aaral na maunawaan at magawa ng tama ang sulatin sa Filipino. Kung hindi maunawaan ng mga mag-aaral ang pagsulat, Malaki ang posibilidad na hindi sila makagawa ng maayos na sulatin gaya ng inaasahan. Kaya't napakahalaga na maanalisa ang sulatin. Sa pamamagitan nito mauunawaan at maeensayo ang mga mag-aaral upang pagbutihin ang galing sa pagsulat.

Ang pag-alam at pagkatuto ng salitang banyaga ay mainam na gawain sa isip na pinalolooban ng pakikinig, pagsasalita, pagbabasa at pagsusulat. Ayon sa ekspertong lingwistiko na si Krashen (2013) maaa rin kang matuto ng pangalawang lenguwahe sa dalawang paraan: maaaring taglay na ito, simula bata pa habang lumalaki ka kung dalawang lenguwahe ang naririnig mo ng regular o natutunan mo lamang, pag-aaral sa batayan ng lenguwahe estruktira at bokabularyo. Maraming salik ang nakakaapekto sa talento ng mag-aaral sa pagsulat sa Filipino, kasama dito ang edad, kasarian, paligid, at mga salik na motibasyon.

Ayon kay Magpantay ( 2011 ), ang pagpili ng angkop na metodo o pamamaraan sa pagtuturo upang makamit ang epektibong pagkatuto ay nakasalalay sa guro. Sa pamamagitan nito nakukuha ang kawilihan ng mga mag-aaral upang making sa aralin. Sa tuwina ay kailangang makabuo sila ng mga dulog na aangkop sa mga pagbabagong nagaganap sa Sistema ng edukasyon.

Ayon kay Balitao (2015), malilinang ang kasanayan ng mga mag-aaral sa pagsisiyasat, pagsusuri, pagsasaliksik, mapanuring pag-iisip, mabisang komunikasyon at pag-unawa sa mga nangyayari sa kapaligiran na ginagalawan ng mga mag-aaral.

Binanggit nina Varona at Mandado (2020), ang kasanayan ng pagsasalita ay kakayahan at kasanayan ng tao na maihayag ang kaniyang ideya sa pamamagitan ng wikang nauunawaan ng kanyang kausap.

Napili ang pananaliksik na ito upang maturuan nang tamang pagsulat ng mga sulatin ang mga mag-aaral ng Buenavista Integrated National High School sa pagsulat ng mga sanaysay. Ang pananaliksik na ito ay magsisilbing halimbawa sa mga mag-aaral ng senior high school ng Buenavista Integrated National High School upang sila ay matutong gumawa ng isang pananaliksik.

\section{LAYUNIN}

Ang pag-aaral na ito ay layuning kilalanin, ilarawan, ipangkat at suriin ang mga karaniwang gramatikang pagkakamali ng mga piling Senior High School sa pagsulat at kaalaman sa linggwistikong kasanayan.

Binibigyang pansin din nito na ang mga makakalap na kasagutan sa mga sumusunod na katanungan;

1. Ano-ano ang karaniwang gramatikang pagkakamali ng mga tagatugon sa pagsulat ng sanaysay kaugnay sa:

1.1. Pagbabaybay;

1.2. Gamit ng mga salita ; at

1.3. Pagbabantas?

2. Ano ang mga salik panghikayat sa pagsulat ng sanaysay ng mga tagatugon batay sa:

2.1. Interes ;

2.2. Kakayahan ; at

2.3. Istratehiya sa pagsulat? 


\section{EPRA International Journal of Research and Development (IJRD)}

3. Ano ang antas ng kaalaman sa linggwistikong kasanayan ng mga tagatugon sa:

3.1. Istruktura ng salita ;

3.2. Pagbuo ng pangungusap ; at

3.3. Bokabularyo/pagkakahulugan ng salita?

4. May makabuluhan bang kaugnayan ang mga salik panghikayat sa pagsulat ng sanaysay sa antas ng kaalaman sa linggwistikong kasanayan ng mga tagatugon?

5. May makabuluhan bang kaugnayan ang karaniwang gramitikang pagkakamali sa pagsulat ng sanaysay sa antas ng kaalaman ng linggwistikong kasanayan ng mga tagatugon?

\section{METODOLOHIYA NG PANANALIKSIK}

Ang kabanatang ito ay maglalahad ng disenyo, kaligiran o lokal, tagatugon sa pananaliksik, instrumento ng pananaliksik, paglikom ng datos at limitasyon ng pag-aaral.

\section{Disenyo ng Pananaliksik}

Ang mananaliksik ay gumamit ng pamamaraan ng deskriptibong pananaliksik kasama ng pag-aanalisa ng datos. Binigyang pansin ng pananaliksik na ito ang mga salik na nakakaapekto sa paggawa ng mali sa gramatika ng Senior High School sa Technical-Vocational-Livelihood Industrial Arts Shielded Metal Arc Welding, TechnicalVocational-Livelihood Home Economics Caregiving at Academic-Humanities and Social Sciences ng Buenavista Integrated National High School para sa taong 2020-2021 na pagsulat. Mga tanong ang ginamit upang makalap ang mga salik na nakakaapekto sa mga mag-aaral sa paggawa ng mali sa gramatika sa pagsulat ng Filipino. Ang mga sulating nagawa ay itatama at inaanalisa ang maling gramatika at statistically treatment para malaman ang porsyento at karaniwang pagkakamali sa gramatika.

Si Cohen et.al (2011) ay nagmamalasakit sa kondisyon/relasyon na umiiral sa oras ng pananaliksik at upang saliksikin ang mga dahilan sa isang partikular na napapanahong pangyayari.

\section{Tagatugon sa Pananaliksik}

Ang mga tagatugon na ginamit sa pananaliksik ay binubuo ng mag-aaral sa Senior High School sa Technical-Vocational-Livelihood Industrial Arts Shielded Metal Arc Welding, Technical-Vocational-Livelihood Home Economics Caregiving at Academic-Humanities and Social Sciences ng Buenavista Integrated National High School para sa taong 2020-2021 na may isang daan walumpu't siyam (189) kabuuang populasyon ng mga tagatugon ay nagamit.

\section{Paraan ng Pananaliksik}

Ang mananaliksik ay gumawa ng talatanungan at pagsusulit na kasama ang pagsulat ng isang sanaysay na may rubriks nan a pinagbabatayan. Ibinigay na gawain sa isang daan walumpu't siyam (189) ng mag-aaral sa Senior High School sa Technical-Vocational-Livelihood Industrial Arts Shielded Metal Arc Welding, TechnicalVocational-Livelihood Home Economics Caregiving at Academic-Humanities and Social Sciences ng Buenavista Integrated National High School para sa taong 2020-2021. Ang nagawang gawain ay inalisa ng ekspertong guro sa Filipino upang malaman ang pagkakamali na nagagawa ng mag-aaral na tagatugon. Ang inayos na mga talatanungan ay pinasagutan sa mga mag aaral sa pamamagitan ng paggamit ng google form. Ang papel ay isinaayos at iniwasto para malaman ang karaniwang pagkakamali sa gramatika ito ay ang mga pagpapalaki ng letra, baybay, paglalagay ng pangalan, maling pagpili ng salita, tamang bantas, gamit ng panghalip, maling pang-ukol, pangatnig, gamit ng pang-abay at pang-uri, gamit ng artikulo, aspeto ng pandiwa simuno at panag-uri agreement at pagkawala ng salita. Gamit ang mga tanong sa pangangalap ng mga salik na nakakaapekto sa mga mag-aaral sa paggamit ng maling gramatika.

\section{Instrumento ng Pananaliksik}

Upang maisaayos ang porsyento ng ibat ibang uri ng mga klase ng mali na nagagawa ng mga tagatugon, ang porsyento $(\mathrm{P}) \mathrm{ng}$ formula ang ginamit.

$$
\mathrm{P}=\frac{\mathrm{F}}{\mathrm{N}} \times 100 \%
$$




\section{EPRA International Journal of Research and Development (IJRD)}

Kung saan:

$$
\begin{aligned}
& \mathrm{F}=\text { bilang ng maling nagagawa } \\
& \mathrm{N}=\text { bilang ng tagatugon }
\end{aligned}
$$

Patungkol naman sa lebel ng panghikayat ng mga mag-aaral sa sulating teknikal ang weighted mean ay ginamit.

Gabay para sa interpretasyon upang malaman ang salik panghikayat at karaniwang gramatikang pagkakamali sa pagsulat ng sanaysay. Gamitin ang iskala:

Saklaw
5
4
3
2
1

Gabay sa Interpretasyon
lubos na sumasang-ayon
sumasang-ayon
di-gaanong sumasang-ayon
hindi sumasang-ayon
lubos na hindi sumasang-ayon

\section{Istatistikal na Pamamaraan}

Ang sumusunod na gamit na pang-istatistika ay upang magbigay ng solusyon at pag-aaral sa problema na sinaliksik. Ang weighted mean at standard deviation ay ginagamit upang matukoy ang mga salik panghikayat at karaniwang garamatikang pagkakamali na nagagawa na ng mag-aaral sa Senior High School sa TechnicalVocational-Livelihood Indutrial Arts Shielded Metal Arc Welding, Technical-Vocational-Livelihood Home Economics Caregiving at Academic-Humanities and Social Sciences ng Buenavista Integrated National High School para sa taong 2020-2021 ng Magdalena.

\section{PAGLALAGOM, KONKLUSYON, AT REKOMENDASYON} Paglalagom

Ang kabanatang ito ay naglalaman ng mga kinalabasan, konklusyon, at rekomendasyon ng pag-aaral.

Ang pag-aaral na ito ay layuning kilalanin, ilarawan, ipangkat at suriin ang mga pagkakamali ng piling Senior High School sa Technical-Vocational-Livelihood Industrial Arts Shielded Metal Arc Welding, TechnicalVocational-Livelihood Home Economics Caregiving at Academic-Humanities and Social Sciences sa pagsulat at upang malaman ang mga salik na nakakaapekto sa paghihikayat sa mga nasabing uri ng pagkakamali.

Binibigyang pansin din nito na ang mga makakalap na kasagutan sa mga sumusunod na katanungan;

Ano- anong ang karaniwang gramatikang pagkakamali ng mga tagatugon sa pagsulat ng sanaysay ay may kaugnayan sa pagbabaybay, gamit ng mga salita at pagbabantas.

Ano ang mga salik panghikayat sa pagsulat ng sanaysay ng mga tagatugon batay sa interes, kakayahan at istratehiya sa pagsulat.

Ano ang antas ng kaalaman sa linggwistikong kasanayan ng mga tagatugon sa istruktura ng salita, pagbuo ng pangungusap at bakabularyo/ pagkakahulugan ng salita.

May makabuluhan bang kaugnayan ang mga salik panghikayat sa pagsulat ng sanaysay sa antas ng kaalaman sa linggwistikong kasanayan ng mga tagatugon?

May makabuluhan bang kaugnayan ang karaniwang gramatikang pagkakamali sa pagsulat ng sanaysay sa antas ng kaalaman ng linggwistikong kasanayan ng mga tagatugon?

Ang mga datos sa nasabing pag-aaral ay nagmula sa istatistikal na pamamaraan ay ginamit upang magbigay ng solusyon at pag-aaral sa problema na sinaliksik. Ang Weigthted Mean at Standard Deviation ay ginamit upang matukoy ang mga salik panghikayat at karaniwang gramatikang pagkakamali na nagagawa ng mag-aaral sa araling Filipino ng Senior High School sa Buenavista Integrated National High School.

Patunay na ang antas ng karaniwang gramatikang pagkakamali ng mga mag-aaral sa pagsulat ng sanaysay kaugnay s pagbabaybay, gamit ng mga salita, at pagbabantas ay may puna na sumasang-ayon at literal na paliwanag na mataas.

Ipinakikita sa antas ng salik panghikayat sa pagsulat ng sanaysay ng mga mag-aara batay sa Interes, kakayahan, at Istratehiya sa pagsulat ay mataas ang puna na sumasang-ayon at literal na paliwanag na mataas.

Nagpapakita naman ang antas ng kaalaman sa lingguwistikong kasanayan ng mga mag-aaral sa Istruktura ng salita, pagbuo ng pangungusap, at Bokabularyo/pangkahulugan ng salita ay may mapaglarawang katumbas ng kasiya-siya.

Nagpapakita ang makabuluhang kaugnayan ay mga salik panghikayat sa pagsulat ng sanaysay sa antas ng kaalaman sa lingguwistikong kasanayan ng mag-aaral. Batay sa datos na nakalap, ipinapakita nito na “ May 
makabuluhang Kaugnayan ng mga salik panghikayat sa pagsulat ng sanaysay sa antas ng kaalaman sa lingguwistikong kasanayan ng mga mag-aaral".

Ipinapakita din nito an ang walang bisang palagay na "walang makabuluhang kaugnayan ng mga salita panghikayat sa pagsulat ng sanaysay sa antas ng mga tagatugon" ay huwag tanggapin, Ipinapakita nito na " May makabuluhang " kaugnayan sa pagitan nila.

\section{Konklusyon}

Ayon sa mga inilahad na suliranin, nabuo ang mga konklusyon na:

1. Ang kabisaan sa pagkatuto ng mga mag-aaral sa pagsulat ng sanaysay sa Filipino ay naging positibo at tinanggap ng mananaliksik batay sa mga tanong at pagsusulit na ginawa. Ayon sa mga krayteryang inilahad sa pagtatanong at pagtataya ay naging resulta na may kabuuang interpretasyong mataas. Ayon sa pag-aaral at mga naging kasagutan ng mag-aaral sa mga tanong at pagtataya isinagawa ay nagkaroon ng interpretasyong mataas ang kinalabasan.

2. Ang antas ng kaalaman na ipinakita ng mga mag-aaral sa lingguwistikong kasanayan sa pagtataya na may kinalaman sa istruktura ng salita, pagbuo ng pangungusap, at bokabularyo / pangkahulugan ng salita ang naging resulta ay may kabuuang interpretasyon na kasiya-siya. Napagalaman na ang mga mag-aaral ay may kakayahang bumuo ng mga pangungusap at gayundin sa pagbibigay ng tamang kahulugan sa mga salita na kanilang isinulat.

3. Ang antas ng kaalaman ng mga mag-aaral na ipinamalas sa pagsulat ng sanaysay sa antas ng kaalaman sa lingguwistikong kasanayan, ay ipinakita din ng datos na nakalap na walang bisang palagay na " walang makabuluhang kaugnayan ng mga salik panghikayat sa pagsulat ng sanaysay sa antas ng kaalamang lingguwistikong kasanayan ng mga tagatugon", sa pagkatuto ng mga mag-aaral batay sa pagsulat ng sanaysay ay nakakuha ng "May makabuluhang" Kaugnayan sa pagitan nila. Sa panig ng mga mag-aaral napatunayan sa pag-aaral na sila ay may kakayahan na sumulat ng isang sanaysay batay sa kanilang kakayahan at nalalaman sa lingguwistikong kasanayan sa pagbuo ng mga pangungusap at mga salitang napapaloob dito.

\section{BIBLIYOGRAPIYA}

\section{A. Mga Aklat}

1. Bartholomae (2014) Pagkatuto ng lengguwahe sa konteksto. Campbridge: Campbridge University Press

2. Cohend et.al (2007) A Look at Research in Education. Singapore: Pearson Education

3. Krashen (2013). Ang teorya ng pangalawang lengguwahe sa Acquisition. Oxford: Oxford University Presss

4. Magpantay, R. (2011). "Pag-unawa sa Pagbasa at Performans sa Filipino ng mga Mag-aaral sa Ikaapat na Taon ng mga Paaralang Sekundarya"

\section{B. Dekuryenteng Materyales}

1. Bernard R. Balitao, Martiniano D. Buising, Edward D.J. Garcia, Apollo D. De

2. Guzman, Juanito L. Lumibao, Jr., Alex P. Mateo, at Irene J.

3. Mondeja(2015),Ekonomiks, Araling Panlipunan Gabay sa Pagtuturo

4. Chapter II, Review of Related Literature. Hinango mula sa

5. http://repository.ump.ac.id/7159/3/Cahyani\%20Wulandari\%20BAB\%20II.pdf

6. Fe A. Varona, Juliet O. Mandado (2020) Ang Kasanayang Pasalita Gamit ang Kagamitang Multimidya sa Antas Tersyarya https://www.ajhssr.com/wp-content/uploads/2020/12/Y20412180186.pdf 